\title{
Improved metabolic control using glucose monitoring systems leads to improvement in vibration perception thresholds in type 1 diabetes patients
}

\author{
Lars B. Dahlin ${ }^{1,2} \cdot \operatorname{Targ}$ Elgzyri $^{3} \cdot$ Magnus Löndahl $^{4} \cdot$ Linnéa Ekman $^{1} \cdot$ Eero Lindholm $^{3}$ (])
}

Received: 22 August 2019 / Accepted: 30 October 2019 / Published online: 8 November 2019

(C) The Author(s) 2019

\begin{abstract}
Aims Few studies have examined how improved metabolic control might influence vibration perception thresholds (VPTs). The aim of this study was to evaluate if improved $\mathrm{HbA}_{1 \mathrm{c}}$ can influence vibration thresholds in adults with type 1 diabetes (T1DM).

Methods VPTs were investigated at six frequencies (4-125 Hz) using VibroSense Meter in the sole of the foot at two occasions in 159 T1DM patients, at the heads of the first and fifth metatarsal bones, i.e. MTH1 and MTH5, respectively. The participants were divided into three groups: group A: $\mathrm{HbA}_{1 \mathrm{c}}$ improved by more than $1 \mathrm{mmol} / \mathrm{mol}(n=95)$, group B: $\mathrm{HbA}_{1 \mathrm{c}}$ deteriorated by more than $1 \mathrm{mmol} / \mathrm{mol}(n=48)$ and group $\mathrm{C}: \mathrm{HbA}_{1 \mathrm{c}}$ unchanged $( \pm 1 \mathrm{mmol} / \mathrm{mol})(n=16)$ compared to baseline.

Results In group A, the mean $z$-score, reflecting the combined effect of all VPTs, improved being lower at the follow-up than at the baseline [0.2 ( -0.3 to 1.2$)$ vs. -0.1 ( -0.7 to 0.8$), p=0.00002]$. VPTs improved at 4 and $64 \mathrm{~Hz}$ at both MTH1 (metatarsal head 1) and MTH5. The VPTs at $125 \mathrm{~Hz}$ frequency improved at MTH5, but not at MTH1. No significant differences were seen in group B or group C.

Conclusions Lower $\mathrm{HbA}_{1 \mathrm{c}}$ and lower VPTs in T1DM patients were associated with improved VPT, suggesting a reversible effect on nerve function by improved metabolic control.
\end{abstract}

Keywords Diabetes $\cdot$ Neuropathy $\cdot$ Continuous glucose monitoring $\cdot$ Flash glucose monitoring $\cdot$ Vibration perception thresholds $\cdot \mathrm{HbA}_{1 \mathrm{c}}$

\section{Background}

Diabetic neuropathies are common, and the most common form of neuropathy is distal symmetric polyneuropathy (DSPN). It is estimated that prevalence of DSPN in patients

Managed By: Antonio Secchi.

Eero Lindholm

Eero.Lindholm@med.lu.se

1 Department of Translational Medicine - Hand Surgery, Lund University, Malmö, Sweden

2 Department of Hand Surgery, Skåne University Hospital, Malmö, Sweden

3 Department of Clinical Sciences, Endocrinology, Lund University, Jan Waldenströmsgata 24, 20502 Malmö, Sweden

4 Department of Clinical Sciences, Endocrinology, Lund University, Lund, Sweden with type 1 diabetes (T1DM) is at least $20 \%$ after 20 years of disease duration [1]. Although DSPN is often considered irreversible, some studies suggest that both peripheral neuropathy and autonomous neuropathy can be reversed in specific cases [2-5], even if structural changes are present with degeneration and regenerative clusters [6]. Normalization of blood glucose by pancreas transplantation can improve nerve function in T1DM patients with DSPN [2], although severe nerve fibre loss seems to be irreversible [7]. In obese patients with type 2 diabetes (T2DM), gastric bypass leads to improvement in both Neuropathy Symptom Score and Neuropathy Deficit Score 6 months after surgery and this improvement seems to be at least partially independent of the improvement in $\mathrm{HbA}_{1 \mathrm{c}}$ [5]. Lifestyle interventions in patients with impaired glucose tolerance resulted in improvement in intraepidermal nerve fibre density (i.e. small diameter nerve fibres) despite rather modest improvements in metabolic markers [8]. Similar data have been obtained regarding autonomic neuropathy as improvement 
in metabolic control can improve heart rate variability in T1DM patients with early cardiac autonomic neuropathy (CAN), while it continued to deteriorate in patients with more advanced CAN [3].

Studies on the effects of improved metabolic control on DSPN in T1DM and T2DM are scarce. A recent study in 25 patients with diabetes investigated nerve fibre density measured by corneal confocal microscopy in both T1DM and T2DM during 24-month follow-up. Increase in nerve fibre density was significantly associated with the reduction in $\mathrm{HbA}_{1 \mathrm{c}}$ from baseline to follow-up [4].

The effect of improved metabolic control on vibration perception thresholds (VPTs) has been so far mostly disappointing. A recent review by Callaghan et al. concluded that randomized control trials on enhanced glucose control in T1DM patients show effect on some measured parameters (different nerve conduction velocities), but no improvement in VPTs although a meta-analysis showed a marginally significant difference in VPTs in favour of intensified glucose control [9]. The largest study followed 102 patients (48 with intensified treatment/54 standard insulin treatment) for 7.5 years [10]. The tibial, peroneal and sural nerve velocities showed less deterioration in the intensive treatment group compared to the standard treatment. However, no difference in VPTs, measured by using a biothesiometer, was seen. A small study in Japanese patients with T2DM could, however, show a positive effect of enhanced short-term (20 days) glycaemic control, which resulted in improved vibration sensation measured with 64-Hz Rydel-Seiffer tuning fork [11]. None of the 31 patients had neuropathic symptoms, and the duration of diabetes was rather short (10 years), suggesting that patients that were studied did not have an advanced diabetic neuropathy. A recent study on newly diagnosed patients with T2DM could demonstrate that intensive treatment leading to normalization of $\mathrm{HbA}_{1 \mathrm{c}}$ (from $81.4 \mathrm{mmol} / \mathrm{mol}(9.6 \%)$ to $41.4 \mathrm{mmol} / \mathrm{mol}(6.0 \%)$ led to long-term improvement in vibration perception thresholds measured by the biothesiometer (VPT frequency $120 \mathrm{~Hz}$ ) [12].

Multifrequency vibrometry is a novel method for assessment of neuropathy. VPTs are measured at six frequencies $(4,8,16,32,64$ and $125 \mathrm{~Hz})$ at the sole of the foot. We have recently shown that VPTs at low frequencies (4 to $8 \mathrm{~Hz}$ ) are a better indicator for the risk of developing diabetic foot ulcers than higher frequencies (like 64 or $125 \mathrm{~Hz}$ ). Low frequencies were also associated with certain neuropathic symptoms like gait or balance problems or weakness of the foot [13].

The aim of this study was to examine long-term effects of metabolic control on VPTs measured by multifrequency vibrometer.

\section{Research design and methods}

\section{Patients and methods}

In total, 215 T1DM patients, attending the department of Endocrinology, Skåne University Hospital, Malmö, Sweden, were examined twice during the period between 2015 and 2018. Patients, who had $\mathrm{HbA}_{1 \mathrm{c}}$ measured within 3 months at the time of the inclusion and during the follow-up visit $(N=161)$, were selected. One patient having hypoglycaemia at the time of the visit was excluded as well as one patient receiving chemotherapy since these conditions could affect the VPTs. Finally, 159 patients (73 males and 86 females) were included. Patients were examined the second time after 1-3 (mean $1.8 \pm 0.5$ ) years. Vibration perception thresholds were measured at MTH1 and MTH5 with a standard VibroSense Meter (VibroSense Dynamics, Malmö, Sweden). The method has been described previously in detail $[13,14]$. In the statistical analysis, only VPTs that were measured at the right foot were used.

At the same time (spring 2015), flash glucose monitoring (FGM) was introduced at the clinic. At follow-up visit, 128 patients had either FGM $(n=109)$ or other types of continuous glucose monitoring system (CGM) $(n=19)$. During the study period, one patient had CGM at inclusion, but discontinued it shortly after the basal visit and 30 patients did only use traditional self-monitoring of blood glucose (SMBG) by finger prick.

$\mathrm{HbA}_{1 \mathrm{c}}$ was measured using either Capillarys 3 TERA Haemoglobin A1c Kit-program (Sebia Benelux SCS, Belgium) with $\mathrm{CV}$ of $3 \%$ or Afinion ${ }^{\mathrm{TM}}$ AS100 Analyzer (Abbott Laboratories, Chicago, Illinois, USA) with CV 4\% at low $\mathrm{HbA}_{1 \mathrm{c}}$ (mean $43.6 \mathrm{mmol} / \mathrm{mol}(6.1 \%)$ ) and $2.6 \%$ at high $\mathrm{HbA}_{1 \mathrm{c}}$ (mean $65.8 \mathrm{mmol} / \mathrm{mol}(8.2 \%)$ ). External quality assessment of $\mathrm{HbA}_{1 \mathrm{c}}$ measurements is organized by the non-profit organization Equalis [15], and both methods are traceable to the International Federation of Clinical Chemistry and Laboratory Medicine (IFCC) Ref. [16]. Afinion ${ }^{\mathrm{TM}}$ method was used for 5 measurements at the baseline and 45 times at the follow-up. The $\mathrm{HbA}_{1 \mathrm{c}}$ and the change in $\mathrm{HbA}_{1 \mathrm{c}}$ were similar regardless of which method was used (data not shown).

To evaluate the effects of metabolic control on VPTs, patients were divided into three different groups: group A: those who had improved their metabolic control more than $1 \mathrm{mmol} / \mathrm{mol}$, group $\mathrm{B}$ : patients whose $\mathrm{HbA}_{1 \mathrm{c}}$ had increased more than $1 \mathrm{mmol} / \mathrm{mol}$ and group $\mathrm{C}$ : patients whose $\mathrm{HbA}_{1 \mathrm{c}}$ was similar $( \pm 1 \mathrm{mmol} / \mathrm{mol})$ compared to baseline. 


\section{Statistical analysis}

Data on normally distributed values are presented as mean \pm standard deviation (SD). Vibration thresholds, diabetes duration and S-triglycerides were not normally distributed and are given as median and 25th and 75th percentile. Because VPTs increase with increasing frequency, a $z$-score for each frequency was calculated using the formula $z=(x-\mu) / \sigma$, where $x$ is the VPT value, while $\mu$ and $\sigma$ are the age- and gender-specific mean and standard deviation, respectively, for a normal population. A mean $z$-score for each observation was then calculated from all individual $z$-scores and gave an estimate of all VPT frequencies together. Wilcoxon signed-rank test was used to compare VPTs at the baseline and at follow-up visit. To correct for multiple comparisons, the significance level was defined as $p=0.004(0.05 / 13)$. IBM SPSS Statistics (Statistical Package for the Social Sciences, SPSS Inc., Chicago, Il, USA) version 25 was used for all statistical analyses.

\section{Results}

In total, 95 patients had lower $\mathrm{HbA}_{1 \mathrm{c}}$ at the follow-up visit than at baseline (group A) (Table 1). $\mathrm{HbA}_{1 \mathrm{c}}$ deteriorated from baseline in 48 patients (group $\mathrm{B}$ ). $\mathrm{HbA}_{1 \mathrm{c}}$ changed $1 \mathrm{mmol} / \mathrm{mol}$ or less in 16 patients (group C). Baseline $\mathrm{HbA}_{1 \mathrm{c}}$ was higher in group A as compared to group B $(66.3 \pm 13.5$ vs. $56.2 \pm 10.3 \mathrm{mmol} / \mathrm{mol}, p=0.00001)$, but lower at followup $(56.5 \pm 11.6$ vs. $62.8 \pm 11.7 \mathrm{mmol} / \mathrm{mol}, p=0.003)$. $\mathrm{HbA}_{1 \mathrm{c}}$ in group $\mathrm{C}$ did not differ from group $\mathrm{A}$ or $\mathrm{B}$, neither at baseline nor at follow-up. Patients, who switched from SMBG to either FGM or CGM during the study period, reduced their $\mathrm{HbA}_{1 \mathrm{c}}$ significantly compared to those who continued with SMBG during the whole study period $[6.1 \pm 9.5$ vs. $0.7 \pm 8.0 \mathrm{mmol} / \mathrm{mol}(0.6 \%$ vs. $0.1 \%), p=0.01]$. The serum lipid values did not change between visits.
Age, age at onset, diabetes duration or serum lipid values did not differ between the groups. The mode of insulin delivery was similar in groups A and B (24.2\% vs. $29.2 \%$, respectively). Insulin pump was used more frequently in group C than in other two groups (62.5\%).

Table 2 shows the VPTs for the different groups based on the change in $\mathrm{HbA}_{1 c}$. In group A, vibration perception thresholds were significantly improved at the followup visit $[z$-score $0.2(-0.3$ to 1.2$)$ vs. -0.1 ( -0.7 to 0.8 ), $p=0.00002]$. No significant differences in the mean $z$-scores were seen in patients with deteriorated or unchanged metabolic control.

In group A, VPTs at the $4 \mathrm{~Hz}$ frequency were significantly lower both at MTH1 [96.2 (91.7-108.7) vs. 95.1 (89.9-102.4) dB, $p=0.003]$ and MTH5 [97.8 (92.5-106.8) vs. $94.2(90.2-101.9) \mathrm{dB}, p=0.000003]$ at the follow-up visit compared to baseline. VPTs at $64 \mathrm{~Hz}$ were also significantly lower at follow-up at both localizations [128.6 (119.0-139.7) vs. $125.6(114.9-135.8) \mathrm{dB}, p=0.0002$ and $127.9(120.3-138.0)$ vs. $126.4(117.6-135.1) \mathrm{dB}$, $p=0.00006$, respectively]. VPTs at the $125 \mathrm{~Hz}$ frequency were lower at follow-up in group A at MTH5, but not at MTH1. In group A, there were also differences in VPTs at 8 and $32 \mathrm{~Hz}$ frequencies (both MTH1 and MTH5), but these were not statistically significant when corrected for multiple comparisons (13).

In group B, the VPTs at $64 \mathrm{~Hz}$ frequency at MTH5 were lower at follow-up compared to baseline, although the difference was not significant when considering multiple comparisons. In patients with unchanged $\mathrm{HbA}_{1 \mathrm{c}}$ (group C), both 16 and $64 \mathrm{~Hz}$ were lower at the follow-up; however, the difference was not significant after correction for multiple comparison.

In group A, 10 patients used CGM and 15 patients used SMBG only. At follow-up, both of these subgroups had lower VPTs measured at MTH5 for the $4 \mathrm{~Hz}$ frequency than at baseline [CGM $96.5(92.1-103.2) \mathrm{dB}$ vs. 92.6 (82.6-1001.2) dB, $p=0.02$; SMG 97.6 (94.7-106.6) dB
Table 1 Patient characteristics at baseline and change in $\mathrm{HbA}_{1 \mathrm{c}}$ from baseline categorized according to change in the $\mathrm{HbA}_{1 \mathrm{c}}$

\begin{tabular}{llll}
\hline & Group A & Group B & Group C \\
\hline $\mathrm{N}(\mathrm{M} / \mathrm{F})$ & $95(41 / 54)$ & $48(23 / 25)$ & $16(9 / 7)$ \\
Age (years) & $47.2 \pm 15.7$ & $46.8 \pm 15.5$ & $50.8 \pm 17.1$ \\
Age at onset (years) & $25.3 \pm 15.6$ & $25.6 \pm 13.4$ & $23.4 \pm 13.3$ \\
Duration (years) & $16.9[7.9-34.4]$ & $19.6[9.0-31.5]$ & $27.5[17.7-36.0]$ \\
Height $(\mathrm{cm})$ & $172.1 \pm 11.2$ & $172.8 \pm 15.3$ & $174.4 \pm 9.6$ \\
Weight $(\mathrm{kg})$ & $77.4 \pm 16.3$ & $73.6 \pm 12.3$ & $79.3 \pm 15.7$ \\
$\mathrm{HbA}_{\mathrm{lc}}(\mathrm{mmol} / \mathrm{mol}) /(\%)$ & $66.3 \pm 13.5(8.2 \pm 1.2)$ & $56.2 \pm 10.3(7.3 \pm 0.9)^{\mathrm{a}}$ & $61.3 \pm 11.5(7.8 \pm 1.1)$ \\
$\Delta \mathrm{HbA}_{\mathrm{c} \mathrm{mmol} / \mathrm{mol}) /(\%)}$ & $-9.8 \pm 8.6(-0.9 \pm 0.8)$ & $6.6 \pm 4.3(0.6 \pm 0.4)^{\mathrm{a}}$ & $0.3 \pm 0.8(0.0 \pm 0.1)^{\mathrm{a}}$ \\
\hline
\end{tabular}

Wilcoxon sign rank test was used for S-triglycerides and duration and paired $t$ test for other variables. Group A: $\mathrm{HbA}_{1 \mathrm{c}}$ improved by more than $1 \mathrm{mmol} / \mathrm{mol}$, group B: $\mathrm{HbA}_{1 \mathrm{c}}$ deteriorated by more than $1 \mathrm{mmol} /$ mol, group $\mathrm{C}: \mathrm{HbA}_{1 \mathrm{c}}$ unchanged $( \pm 1 \mathrm{mmol} / \mathrm{mol})$ compared to baseline. ${ }^{\mathrm{a}} p<0.0001$ compared to group A 
Table 2 Comparison of change in vibration perception thresholds at baseline versus follow-up in different categories of $\mathrm{HbA}_{1 \mathrm{c}}$ change

\begin{tabular}{llll}
\hline Frequency & Group A & Group B & Group C \\
\hline MTH1 $4 \mathrm{~Hz}(\mathrm{~dB})$ & $3.1[-2.3 \text { to } 7.4]^{\mathrm{a}}$ & $0.0[-5.5$ to 3.8$]$ & $3.0[0.0$ to 5.2$]$ \\
MTH1 $8 \mathrm{~Hz}(\mathrm{~dB})$ & $1.7[-1.9$ to 6.6$]$ & $0.0[-3.3$ to 2.3$]$ & $1.0[-8.1$ to 3.2$]$ \\
MTH1 $16 \mathrm{~Hz}(\mathrm{~dB})$ & $0.1[-4.0$ to 6.1$]$ & $-1.1[-5.5$ to 3.7$]$ & $-3.1[-7.8$ to 4.4$]$ \\
MTH1 $32 \mathrm{~Hz}(\mathrm{~dB})$ & $2.2[-3.2$ to 6.4$]$ & $1.2[-2.0$ to 4.5$]$ & $-2.5[-7.7$ to 5.4$]$ \\
MTH1 $64 \mathrm{~Hz}(\mathrm{~dB})$ & $4.7[1.1 \text { to } 10.1]^{\mathrm{b}}$ & $2.2[-3.8$ to 6.9$]$ & $-0.3[-10.6$ to 4.7$]$ \\
MTH1 $125 \mathrm{~Hz}(\mathrm{~dB})$ & $1.8[-2.8$ to 7.0$]$ & $0.0[-4.0$ to 4.8$]$ & $-0.7[-4.2$ to 9.2$]$ \\
MTH5 $4 \mathrm{~Hz}(\mathrm{~dB})$ & $4.0[0.0 \text { to } 8.4]^{\mathrm{c}}$ & $2.7[-2.4$ to 7.7$]$ & $3.8[-2.9$ to 7.3$]$ \\
MTH5 $8 \mathrm{~Hz}(\mathrm{~dB})$ & $2.7[-1.9$ to 7.4$]$ & $1.6[-3.6$ to 6.7$]$ & $1.4[-2.2$ to 9.4$]$ \\
MTH5 $16 \mathrm{~Hz}(\mathrm{~dB})$ & $1.6[-3.7$ to 6.5$]$ & $2.1[-4.4$ to 7.7$]$ & $2.3[-0.8$ to 8.4$]$ \\
MTH5 $32 \mathrm{~Hz}(\mathrm{~dB})$ & $2.1[-3.2$ to 7.2$]$ & $2.5[-3.9$ to 6.9$]$ & $1.6[-2.4$ to 5.3$]$ \\
MTH5 $64 \mathrm{~Hz}(\mathrm{~dB})$ & $5.3[-1.6 \text { to } 13.0]^{\mathrm{c}}$ & $3.1[-1.8$ to 7.4$]$ & $1.5[0.6$ to 7.8$]$ \\
MTH5 $125 \mathrm{~Hz}(\mathrm{~dB})$ & $4.4[-2.1 \text { to } 9.9]^{\mathrm{c}}$ & $2.1[-6.9$ to 7.3$]$ & $0.7[-2.8$ to 13.3$]$ \\
$z$-score $(\mathrm{all})$ & $-0.33[-0.02 \text { to } 0.72]^{\mathrm{c}}$ & $-0.06[-0.18$ to 0.47$]$ & $-0.14[-0.22$ to 0.44$]$ \\
\hline
\end{tabular}

Wilcoxon sign rank test. $p<0.004$ is considered as significant after correction for multiple (13) comparisons. Group $\mathrm{A}$ : $\mathrm{HbA}_{1 \mathrm{c}}$ improved by more than $1 \mathrm{mmol} / \mathrm{mol}$, group $\mathrm{B}$ : $\mathrm{HbA}_{1 \mathrm{c}}$ deteriorated by more than $1 \mathrm{mmol} / \mathrm{mol}$, group C: $\mathrm{HbA}_{1 \mathrm{c}}$ unchanged $( \pm 1 \mathrm{mmol} / \mathrm{mol})$ compared to baseline. Values are change in VPTs [25th-75th percentile]. ${ }^{\mathrm{a}} p<0.004 ;{ }^{\mathrm{b}} p<0.001 ;{ }^{\mathrm{c}} p<0.0001$ vs. $94.1(90.8-101.5) \mathrm{dB}, p=0.03$, baseline vs. follow-up, respectively].

In a subgroup of patients $(N=10)$ in group A with long duration of diabetes ( $>20$ years) and severely impaired VPTs at baseline (mean $z$-score $>2.0$ ), the $4 \mathrm{~Hz}$ frequency improved from baseline to follow-up. VPTs for $4 \mathrm{~Hz}$ were at MTH1 113.0 (108.8-115.0) dB vs. 108.5 (102.2-115.0) dB, $p=0.02$ and at MTH5 $115.0(115.0-115.0) \mathrm{dB}$ versus 110.0 (102.3-115.0) dB, $p=0.04$. For $64 \mathrm{~Hz}$, the VPTs were at MTH1 150.1 (145.9-156.7) dB versus 146.5 (141.9-155.5) $\mathrm{dB}, p=0.02$ and at MTH5 155.4 (147.4-156.5) dB versus 143.9 (139.7-149.1) dB, $p=0.03$, respectively.

\section{Discussion}

The present study has shown that improved metabolic control in patients with T1DM is associated with improved vibrotactile sense observed by lower vibration perception thresholds at low frequencies, i.e. at 4 and $64 \mathrm{~Hz}$. Previous studies in T1DM patients have shown improvement in conduction velocities of the peroneal, median and ulnar nerves, but not in VPTs [9]. In contrast, two other studies, including people with T2DM [11, 12], have shown improvement in vibration perception after intensive glucose control, i.e. one in patients with newly diagnosed diabetes and one with diabetes duration up to 10 years. The improvements in $\mathrm{HbA}_{1 \mathrm{c}}$ in these studies of patients with T2DM were large [19.6 and $41.4 \mathrm{mmol} / \mathrm{mol}$ (1.8\% and 4.6\%), respectively] compared to a rather modest improvement in our present study $[9.8 \mathrm{mmol} / \mathrm{mol}(1.0 \%)$ in group A]. It is possible that patients with T1DM in earlier studies did not have sufficient decrease in $\mathrm{HbA}_{1 \mathrm{c}}$ or that their long diabetes duration was associated with more advanced structural changes that were not reversible. Another explanation could be the difference in the equipment and frequencies used to test VPTs. Thus, in the Stockholm Diabetes Intervention Study, with a diabetes duration similar to ours (intensive treatment group: 18 years and conventional treatment group: 16 years) [10], and with a larger $\mathrm{HbA}_{1 \mathrm{c}}$ reduction [- $\left.25 \mathrm{mmol} / \mathrm{mol}(2,4 \%)\right]$, the biothesiometer measuring VPTs at $100 \mathrm{~Hz}$ frequency was used.

Out of the six frequencies measured in our study, the 4 and $64 \mathrm{~Hz}$ frequencies showed improved VPTs regardless of the site, while the $125 \mathrm{~Hz}$ frequency measured at MTH1 did not show any difference. Our interpretation is that the $4 \mathrm{~Hz}$ frequency is more sensitive to changes in metabolic control than $125 \mathrm{~Hz}$. Another possibility could be that the pressure against the skin varies when using a handheld instrument. An increase in pressure has been shown to give decreased VPTs [17]. In the VibroSense Meter, the contact pressure of the probe against the skin is adjusted prior to the measurement to a force of approximately $0.2 \mathrm{~N}$, and if the pressure would change, it will be corrected during the test.

A long duration of diabetes or an advanced peripheral neuropathy, e.g. more advanced structural changes, already at start could be possible explanations why earlier studies did not show significant improvement in VPTs in patients with T1DM despite the improved metabolic control. In the present study, however, VPTs at $4 \mathrm{~Hz}$ and $64 \mathrm{~Hz}$ improved with improving $\mathrm{HbA}_{1 \mathrm{c}}$ even in patients with a long duration of diabetes and severely impaired VPTs at the baseline.

One limitation of this study is that it is not a randomized trial, but an observational study. The introduction of the FGM and the CGM systems coincided with the present study and was accompanied by larger reductions in $\mathrm{HbA}_{1 \mathrm{c}}$ than was anticipated, which resulted in a larger group of 
individuals with improved metabolic control and a smaller group of individuals with unchanged or impaired $\mathrm{HbA}_{1 \mathrm{c}}$.

Both CGM [18] and FGM [19] decrease glucose variability, and this could be a possible explanation for the improved VPTs. We did not record any measures of glucose variability and therefore cannot answer the question what role it may play. Only 15 patients improved their metabolic control using SMBG. However, the difference in $4 \mathrm{~Hz}$ frequency was still significant, suggesting that metabolic control itself is important.

We did not measure plasma glucose at the time of the investigation. It has been shown that very short-term hyperglycaemia does not influence VPTs [20] even though large improvements in metabolic control during 20 days influenced vibration sensation [11].

In summary, we show that signs of peripheral neuropathy, based on measurements of VPTs, in patients with T1DM may be reversible if metabolic control is improved. As a novel finding, we demonstrate that VibroSense Meter can monitor changes in VPTs after improvement in metabolic control. This can further motivate patients with T1DM to continue to improve their $\mathrm{HbA}_{1 \mathrm{c}}$.

Acknowledgements Open access funding provided by Lund University. This work was supported by the Swedish Governmental Agency for Innovation Systems https://www.vinnova.se/en/ (E.L 1282000 SEK and L.D 921200 SEK) and the Skåne Research and Development http://www.researchweb.org/is/ssvr/ (E.L 180000 SEK). The funders had no role in study design, data collection and analysis, decision to publish or preparation of the manuscript.

\section{Compliance with ethical standards}

Conflict of interest The author declares that they have no conflict of interest.

Ethical standard statement The local ethics committee at Lund University approved the study $(2007 / 386,2015 / 3)$.

Informed consent disclosure Written informed consent was obtained from all participants.

Open Access This article is distributed under the terms of the Creative Commons Attribution 4.0 International License (http://creativeco mmons.org/licenses/by/4.0/), which permits unrestricted use, distribution, and reproduction in any medium, provided you give appropriate credit to the original author(s) and the source, provide a link to the Creative Commons license, and indicate if changes were made.

\section{References}

1. Pop-Busui R, Boulton AJ, Feldman EL et al (2017) Diabetic neuropathy: a position statement by the american diabetes association. Diabetes Care 40(1):136-154. https://doi.org/10.2337/dc16-2042

2. Solders G, Tyden G, Persson A, Groth CG (1992) Improvement of nerve conduction in diabetic neuropathy. A follow-up study
$4 \mathrm{yr}$ after combined pancreatic and renal transplantation. Diabetes 41(8):946-951

3. Burger AJ, Weinrauch LA, D'Elia JA, Aronson D (1999) Effect of glycemic control on heart rate variability in type I diabetic patients with cardiac autonomic neuropathy. Am J Cardiol 84(6):687-691

4. Tavakoli M, Kallinikos P, Iqbal A et al (2011) Corneal confocal microscopy detects improvement in corneal nerve morphology with an improvement in risk factors for diabetic neuropathy. Diabet Med 28(10):1261-1267. https://doi.org/10.111 1/j.1464-5491.2011.03372.x

5. Muller-Stich BP, Fischer L, Kenngott HG et al (2013) Gastric bypass leads to improvement of diabetic neuropathy independent of glucose normalization-results of a prospective cohort study (DiaSurg 1 study). Ann Surg 258(5):760-765. https://doi. org/10.1097/sla.0b013e3182a618b2 (discussion 765-766)

6. Osman AA, Dahlin LB, Thomsen NO, Mohseni S (2015) Autophagy in the posterior interosseous nerve of patients with type 1 and type 2 diabetes mellitus: an ultrastructural study. Diabetologia 58(3):625-632. https://doi.org/10.1007/s0012 5-014-3477-4

7. Havrdova T, Boucek P, Saudek F et al (2016) Severe epidermal nerve fiber loss in diabetic neuropathy is not reversed by longterm normoglycemia after simultaneous pancreas and kidney transplantation. Am J Transpl 16(7):2196-2201. https://doi. org/10.1111/ajt.13715

8. Smith AG, Russell J, Feldman EL et al (2006) Lifestyle intervention for pre-diabetic neuropathy. Diabetes Care 29(6):1294-1299. https://doi.org/10.2337/dc06-0224

9. Callaghan BC, Little AA, Feldman EL, Hughes RA (2012) Enhanced glucose control for preventing and treating diabetic neuropathy. Cochrane Database Syst Rev 6:CD007543. https:// doi.org/10.1002/14651858.cd007543.pub2

10. Reichard P, Nilsson BY, Rosenqvist U (1993) The effect of long-term intensified insulin treatment on the development of microvascular complications of diabetes mellitus. N Engl J Med 329(5):304-309. https://doi.org/10.1056/NEJM199307293290502

11. Fujita Y, Fukushima M, Suzuki H et al (2008) Short-term intensive glycemic control improves vibratory sensation in type 2 diabetes. Diabetes Res Clin Pract 80(1):e16-e19. https://doi. org/10.1016/j.diabres.2007.12.011

12. Ishibashi F, Taniguchi M, Kosaka A, Uetake H, Tavakoli M (2019) Improvement in neuropathy outcomes with normalizing $\mathrm{HbAlc}$ in patients with type 2 diabetes. Diabetes Care 42(1):110-118. https ://doi.org/10.2337/dc18-1560

13. Lindholm E, Londahl M, Fagher K, Apelqvist J, Dahlin LB (2019) Strong association between vibration perception thresholds at low frequencies ( 4 and $8 \mathrm{~Hz}$ ), neuropathic symptoms and diabetic foot ulcers. PLoS ONE 14(2):e0212921. https://doi.org/10.1371/journ al.pone. 0212921

14. Nelander J, Speidel T, Bjorkman A, Dahlin LB (2012) Vibration thresholds are increased at low frequencies in the sole of the foot in diabetes-a novel multi-frequency approach. Diabet Med 29(12):e449-e456. https://doi.org/10.1111/dme.12024

15. Nordin G (2018) Accuracy of HbA1c as monitored by external quality assessment and compared with patient mean values. J Diabetes Sci Technol 12(4):771-779. https://doi.org/10.1177/19322 96818785622

16. Jeppsson JO, Kobold U, Barr J et al (2002) Approved IFCC reference method for the measurement of HbA1c in human blood. Clin Chem Lab Med 40(1):78-89. https://doi.org/10.1515/ cclm.2002.016

17. Lowenthal LM, Hockaday TD (1987) Vibration sensory thresholds depend on pressure of applied stimulus. Diabetes Care 10(1):100-102

18. Garg SK, Voelmle MK, Beatson CR et al (2011) Use of continuous glucose monitoring in subjects with type 1 diabetes on 
multiple daily injections versus continuous subcutaneous insulin infusion therapy: a prospective 6-month study. Diabetes Care 34(3):574-579. https://doi.org/10.2337/dc10-1852

19. Bolinder J, Antuna R, Geelhoed-Duijvestijn P, Kroger J, Weitgasser R (2016) Novel glucose-sensing technology and hypoglycaemia in type 1 diabetes: a multicentre, non-masked, randomised controlled trial. Lancet 388(10057):2254-2263. https://doi. org/10.1016/S0140-6736(16)31535-5

20. Thye-Ronn P, Sindrup SH, Arendt-Nielsen L, Brennum J, Hother-Nielsen O, Beck-Nielsen H (1994) Effect of short-term hyperglycemia per se on nociceptive and non-nociceptive thresholds. Pain 56(1):43-49

Publisher's Note Springer Nature remains neutral with regard to jurisdictional claims in published maps and institutional affiliations. 